\title{
LIV. Reply to a letter of Dr. Marcet to Dr. Bostock, on the subject of the alkali in the animal fluids
}

\section{George Pearson M.D. F.R.S.}

To cite this article: George Pearson M.D. F.R.S. (1812) LIV. Reply to a letter of Dr. Marcet to Dr. Bostock, on the subject of the alkali in the animal fluids, Philosophical Magazine Series 1, 40:175, 321-326, DOI: 10.1080/14786441208638239

To link to this article: http://dx.doi.org/10.1080/14786441208638239

册 Published online: 27 Jul 2009.

Submit your article to this journal $\lceil\pi$

Џll Article views: 2

Q View related articles $\square$ 
LIV. Reply to a Letler of Dr. Marcet to Dr. Bostock, on the Suljeet of the Alkali in the Animal Fluids. By George Pearson, M.D. F.R.S., Eoc.

\section{To Mr. Tilloch.}

SIR, $I_{N}$ your Journal for the preceding month I read the letter of Dr. Marcet addressed to his friend Dr. Bostock, in which he offers the evidence of some experiments to prove that the potash which exists in the animal fluids is in the state of muriat (inuriate), and that the whole of the uncombined alkali is soda. It appears that Dr. Bostock was of opinion that the supposed uncombined alkali was potash, as I provisionally concluded, and not sorla ; but on the representation of evidence just mentioned, he has changed his opinion; and therefore has become the vehicle of Dr. Marcet's letter to the public, confiding, he says, that you Mr. Editor will assent that the experiments stated "must entirely set the question at rest." One authority declaring the question to be entirely set at rest, and the other (the author) affirming that every shadow of doubt is now removed, although I was not ready to believe, as I have had occasion to assert, that more than provisional conclusions are likely to be obtained, I at least expected to find some new contravening testimony. This I was prepared to acknowledge; for, ream soning merely from the known facts, I should have felt no humiliation if new evidence indicated adverse conclusions: Nos non judicis sed indicis personam sustinemus. (F. Bacon,)

But on examining the evicence which it is asserted has produced conviction, "removed every shadow of doubt," and "set the question at rest," I was unable to perceive any new facts to alter my former conclusions. Hence, $I$ might have replied merely by a counter declaration, and reference to nyy unanswered experiments and inferences. As however this molle of procedure may be deemed neither decorous to my opponent and the testimony produced of respectable personal authority, nor satistactory to the public, I respectfully offer the following brief exposition and remarks. The process which Dr. Marcet says authorises his confidence was this :

The saline matters of the serum of blond were procured by evapuration to dryness, incineration, dissolution in water, filtration, evaporation again to dryness, dissolution in acetic acid, dissolution again of the desiccated acetic com-
Vol. 40. No. 175. Nov, 1812.
$\mathrm{X}$
pound 
pound in alcohol ; evapnration of this to dryness, and $f \downarrow-$ sion. The fused mass amouning to about four grains was divided into four parts $-a, b, c, d$.

1. a. 1. "Contained abundance of muriatic acid."

8. Dissolved in water and suffered to evaporate spontaneously, it afforded an efflorscent mass of feathery with cubical crystals.

3. Tartaric acid and oxymuriate of platina manifested the presenze of potash.

Now, I can only infer from these experiments that a muriate present, probably either of soda or of potash, or of both. That potash was present combined, but with what substance is quite equivocal; being only a small fractional part of a grain, it might be united to a double salt ; althongh weakly, yet to be no longer deliquescent. It may also be united to muriatic or other acids, especially the sulphuric and carbonic; but here is no evidence of sola in a free state, and even only equivocal evidence of it as united to muriatic acid. If free soda were present, why was not soda-tartrate of potash observed?

\&. The portion $b$ with sulphuric acid gave sulphate of soda and sulphate of potash. Here the testimony is equivocal, for the sulphate of soda may, and indeed most probably was from the decomposition of muriate of soda by the sulphuric acid, and the sulphate of potash may arise from the decomposition of potash united to some acid, such as carbonic muriatic, \&c. united though weakly to the other salts. Hence I perceive no evidence of soda in 2 free state.

3. The portion $c$ with nitric acid afforded rhomboidal crystals and no prismatical crystals. I will not repeat my objections to any conclusions from the form of crystals, especially in such minute portions of matter as a small part of a grain, set forth so fully in a former paper; but it may be right just to remark that this experiment is inconclusive and unsatisfactory: 1 . becuuse, if all the crystals were nitrate of soda, then all the saline mass must be soda ; or, 2 . if only a part was soda, and the rest was muriate, then this must have been decompounded by the nitric acid: but, 3. if this could happen, then the whole of the rhombs might be from the decompounded muriate of soda: 4 . if the whole of the crystals were rhombs of nitrate of soda, what became of the cubical crystals of muriate of potash ?

4. The portion $d$ with oxymuriate of platina gave a precipitate of potash-oxymuriate of platina, and by evaporation, soda muriate of platina. Hore the questions na- 
tirally occur; 1 . What are the proofs of soda-muriate of platina? 2. What are the proofs that soda-muriate of platina was from free soda, and not from muriate of soda?

To omit nothing supposed to be favourable to the adverse party, it must be noticed that "the carbonaceous alkaline mass" above spoken of after fusion, did not deliquesce on exposure to even damp air. I never met with such a result, at least with expectorated matter and dropsical fluids; and if no deliquescence took place with the salts of serum, it is not unreasonable to account for it from the very small proportion, probably not one fourth of a grain, or at most half a grain of alkali in the whole mass; and this by fusion night be united to form a compound unknown.

To the inferences of my adversary I also object; that it is assumed without testimony, that alcohol dissolved a large proportion of muriate of potash. It is I believe admitted (but it may be an error) that this menstrum dissolves none at all: but if this be an error, I demand the proof.

2. It was not admitted as I reasoned that acetate of soda is non-deliquescent, and therefore the proof 1 offered of the alkali being potash from the deliquescent property of the acetate was eagerly seized to expose my ignorance, by exultingly exclaiming that I had committed a palpable error. 1 acknowledged that I had taken for granted, with most chemists, what 1 subsequently admitted was not a fact: but I am now in a doubtful state of mind with respect to this property : for Professor Berzelins oonfidently assures me that he found by repeated experiments acetate of soda to be uniformly non-deliguescent; and on observing that in my experiment I had found it otherwise, we agreed that probably the different results were owing to the soda I used containing a proportion, however minute, of potash, and which $l$ could not perceive by tartaric acid; whereas that he used was exempt. If this be true, it will be a stronger proof that the alkali is potash, than the united testimonies to prove that it is soda.

3. Dr. Marcet argues, that from principle it may be inferred that sada and not potash is the impreguating alkali, because the latter attracts muriatic acid more sfrongly than the former. This is true in the circumstance of simple elective attraction: but any reasming from this law when more than one menstruum is prescut and twa or more bases, is fallacious; especially when the different substances present are not certainly known : and here I must observe that 1 have never contemplated potash as existing in an uncombined state in the animal fuids, but in reality in combina- 
tion with a destructible acid, or with animal oxide This acid from some trials, I was inclined to propose is the malic acid, but 1 subsequently did not venture to offer 1t: however, $I$ find from the conversation of Professor Berzelius, now in London, that he coincided with me in an analogous, if not a similar result. "You very nearly," said he, " nade a capital discovery, for I have ascertained it is the lactic acid in union with the alkali of the animal fluids." I hope the British public will soon be edified by the translation from the Swedish language of the works of this thost acute chemist, and as I hear by a most able editor. Hence much light will be afforded, especially in animal chemistry. This fact is however only within the record before us, to refute any $\grave{a}$ prior $i$ conclusion from a case of simple elective attraction. I had long consilered the case of this kind noticed by my opponents, for it was too glaring to be unnoticed. If reasoning from principle could be depended upon I would argue; that as all animals either immediately or mediately live upon vegetable matter; and as vegetables very generally contain potash combined with acids, or some other things destructible by fire, it is reasonable to conclude that the fluids of animals must be impregnated with potash in such a state of combination.

1 know it has been inferred by some able chemists that the potash must be united to muriatic or sulphuric acid, and soda must be united to some weaker acid, such as carbonic, lactic, acetous, malic, \&c. agretably to the assumed law that the stronger menstruum unites with the stronger basis, and the weaker menstruum with the neaker basis: but there are so many exceptions to this rule that $I$ apprehend it cannot rightly be termed a law.

Lastly, in his P.S. Dr. Marcet says he has instituted the processes above examined, on a large quantity, some gallons of bullocks blood, with the same results as on small quantities of animal matter. I believe such evidence is inadmissible; for, if mere general statements of results be received as testimony, much error will be liable to be introduced, as the public in these cases cannot be in possession of the means of repeating the experiments and judging of their accuracy. It is to be regretted that the author did not render his experiments instructive by a due detail : however, if they were a mere repetition of his former.ones, the questionable fact would still renain undetermined.

The chemical world may now perhaps be furnished with the means of judging whether or not Dr. Marcet has "re- 
moved every shadow of doubt," by legitimate inductive reasoning. My opponent, not content with proofs by experiment, has endeavoured to command assent by 2 most respectable authority of opinion. But Truth is not the daughter of mere human authority, but of Time producing evidence of sense and of reasun.

$I$ beg permission to make a very few remarks, which althongh justifiable, yet, being personal, will afford but lenten entertainment, and still less instruction to the public.

In making the above authority the vehicle of his letter, my opponent thinks proper to express disapprobation of my mode of controversy, and to more than insinuate I shoutd not have been bonoured with-further notice, but for the "interference" of his friend. Accordingly, but for this fortunate circumstance the public would not have been instructed by his letter now under examination. This cots duct I own, I think, is rather selfsh; for a public-spirited map will always make sacrifices for the benefit of the republic. It is however good, that the interference overcanie the resolution afier frur months obstinate resistance. The head and front of my offending was, it seems, to the extent of an attempt in be jocular, in which I never meant to inflict any wound of the feelings. It grieves me to find that some of my expressions were misconstrued insidiousness:- -non vulnera fidelia amantis, sed osculd llandosta malignantis. In the endeavour to expose the inefficiericy of the proposed method of investigation, and to honour il: lustrious chemists, whose successful methods were unworthily disvalued, I preferred the manner of controversy complained of to the alternative-a serious remonstrance. For, as my affectionate friend, the prince of philologists, now no more! was wont to say, "Cantantes minus via ledit."

In conclusion, 1 -would fain hope that, if this warfare must be continced, special care will be employed that nothing be said, or arise, which can reasonably excite pairfut sensations, in either party. And if it be agreed that our axioms and conclusions are but inductive reasoning 3 , according to known facts, which theretore are ilatile to be subverted * by the facts being muttiplied; whatever be the

\footnotetext{
* Experientize ordo, primo lumen accendit, deinde per fumen iter demonstrat, incipiendo ab experientia ordinata et digesta, -atque ex ea educendo axiomata, atque ex axiomatibus constitutis rursus nova experimenta. -F. Baconis Nivam Orgumam. 
issue, no humiliation nught to be experienced, as the parties will moult no feather.

I have the honour to be, dear sir,

Your most faithful servant,

Gengge Pearson.

P. S. - I have no where charged Dr. Marcet in the terms alleged, viz. that he had committed blunders in reasoning, I can well spare that word blunder from $\mathrm{my}$ vocabulary, having little use for it, although by the law of retaliation amply justifiable.

LV. Of such Portions of a Sphere as have their Attraction expressed by an algebraic Quantity.

The measure of the surface of a sphere involving in its expression the length of the circumference of a circle, it has been thoughr an interesting problem, even so long ago as the time of Pappus, to assign such portions of that surrface as admit of an exact quadrature: and this kind of inquiry has been extended by Enler, and some later writers, to the finding such parts of the solidity as may be exactly cubed.

Now as the attraction of a sphere, on a point at its surface, is expressed by the same kind of transcendental quantity as the surface, or the solidity, it seems a problem equally interesting with those above mentioned, to determine such portions as have their attraction an algebraic quantity.

Let the circle AEFG, fig. 5. (Plate VIII.) be the base of a hemisphere, $\mathrm{AF}$ a diameter, $\mathrm{ABCH}$ a curve touching or meeting the circle at $A$, and having its portions $A B C$, AHC equal and similar to one another. Conceive a right cylinder to be erected on the hase $A B C H$, and to pass through the surface of the hemisphere; it is required to find the attraction of that portion of the. cylinder, that is intercepted by the bemisphere, on a point at $A$, in the direction $A F$. Let a line $A D$, drawn from $A$ to any point $\mathrm{D}$ in the hase, be called $r$; the angle $\mathrm{DAF}, \theta$; Let $\Phi(r, \theta)$ represent a perpendicular to the base at $D$, and extended to the surface of the hemisphere. Then, if $F$ denote the force of the cylindrical portion in question, it is easy 10 see that

$$
\mathbf{F}=2 \iint \frac{\varphi(r, \theta) \cos . \dot{\theta} . \dot{r}}{\sqrt{\varphi(r, \theta)^{2}+r}} \ldots \ldots \ldots \ldots(\alpha) ;
$$

